\title{
SMART VEHICLE TRACKING SYSTEM
}

\author{
Mrs. K.P.Kamble ${ }^{1}$ \\ Lecturer \\ ${ }^{1}$ Department of Electronics and Telecommunication Engineering, YCCE, Nagpur \\ kanchan_114@rediffmail.com
}

\begin{abstract}
It is amazing to know how simple ideas can give a whole new dimension to the tracking and navigation industry and smart vehicle tracking system is used for tracking the vehicles. You can optimize driver routes, save petrol or gas and time, reduce theft and control the vehicle functions.

Many a times it is not required to track your vehicle or target globally. In majority of cases tracking is more restricted to local purposes only, such as tracking movement of vehicle within city, tracking the raw materials within industrial estate or to know the present position of your daughter or son within city.

But unfortunately in the pursuit of making things complex this simple idea is forgotten. This simple yet powerful idea forms the basis of this revolutionary project. All this coupled with a very low cost, a robust design and tremendous market potential makes this model even more attractive.
\end{abstract}

\section{Keywords}

GPS, vehicle tracking, tracking movement.

\section{INTRODUCTION}

The roots of Vehicle Tracking Systems lie in shipping industry. They required some sort of system to determine where each vehicle was at any given time and for how long it travelled.

Initially vehicle tracking systems developed for fleet management were passive tracking system. In passive tracking system a hardware device installed in the vehicle store GPS location, speed, heading and a trigger event such as key on/off, door open/closed. When vehicle returns to a specific location device is removed and data downloaded to computer.

Real time tracking system was required that can transmit the collected information about the vehicle after regular intervals or at least could transmit the information when required by monitoring station. Active systems were developed that transmit vehicle's data in real time via cellular or satellite networks to a remote computer or data centre.

Many vehicle systems that are in use now days are some form of Automatic Vehicle Location (AVL). It is a concept for determining the geographic location of a vehicle and transmitting this information to a remotely located server. The location is determined using GPS and transmission mechanism could be a satellite, terrestrial radio cellular connection from the vehicle to a radio receiver, satellite or nearby cell tower. After capture, the tracking data can be transmitted using any choice of telemetry or wireless communications systems. GSM is the most common used service for this purpose.

In this project a microcontroller is used for interfacing to various hardware peripherals. The current design is an embedded application, which will continuously monitor a

DOI : 10.5121/ijdps.2012.3410 
International Journal of Distributed and Parallel Systems (IJDPS) Vol.3, No.4, July 2012

moving Vehicle and report the status of the Vehicle on demand. For doing so a microcontroller is interfaced serially to a GSM Modem and GPS Receiver. A GSM modem is used to send the position (Latitude and Longitude) of the vehicle from a remote place. The GPS modem will continuously give the data i.e. the latitude and longitude indicating the position of the vehicle.

\section{DESIGN ISSUES}

\subsection{POWER SUPPLY}

The function of regulated power supply is to supply a voltage or current, to a circuit that is operated with certain power supply limits. Regulated power supply is generally an embedded circuit and the output from the regulated power supply is unidirectional, and is always DC.

\subsubsection{REGULATOR IC (7805)}

Regulator IC is a three pin Ic which is used as a voltage regulator. This IC is used to convert unregulated DC current into regulated DC current. Regulator IC used in this system is 7805 . Used to regulate and give voltage of $5 \mathrm{~V}$.

\subsubsection{POWER ADAPTERS}

The $\mathrm{AC}$ adapter, $\mathrm{AC} / \mathrm{DC}$ adapter or $\mathrm{AC} / \mathrm{DC}$ converter is a type of external power supply, often enclosed in a case similar to an AC plug. Other names include plug pack, plug-in adapter, adapter block, domestic mains adapter, line power adapter, or power adapter. AC adapters are generally used with electrical devices and require power to derive the required voltage and power from mains power.

\section{METHODOLOGY}

\subsection{METHODOLOGY}

To find the location of the vehicle, the owner needs to send a message to the vehicle tracking system. When the user request is sent to the number at the modem, the system sends a return reply automatically to that mobile which indicate the position of the vehicle with latitude and longitude.

The software can produce all the reports in quick time.

The methodology consists of modeling of device and below it is explained in steps.

Step 1:

Fix the transmitter of vehicle tracking system in the vehicle. Start the device using the push pull button for on-off device.

\section{Step 2:}

On the other end connect the receiver to a computer using a RS232 cable and start the receiver using the push pull button for on-off device along with the computer.

\section{Step 3:}

A GSM modem in the transmitter sends the position of the vehicle from a remote place to the requesting mobile. The owner will get a message in form of latitude and longitude.

\section{Step 4:}

The information is also transferred to the computer for output using cable RS232. 
International Journal of Distributed and Parallel Systems (IJDPS) Vol.3, No.4, July 2012

a. A scanned map of a city is set as background on screen.

b. Latitude and longitude of the target vehicle is received from GPS receiver.

c. With the help of RF transmitter the received data will be sent to a computer.

d. A software program to plot a point (small circle) as vehicle on scanned map of city will trace the exact location of the vehicle.

\section{IMPLEMENTATION}

\subsection{FLOWCHART FOR TRANSMITTER:}

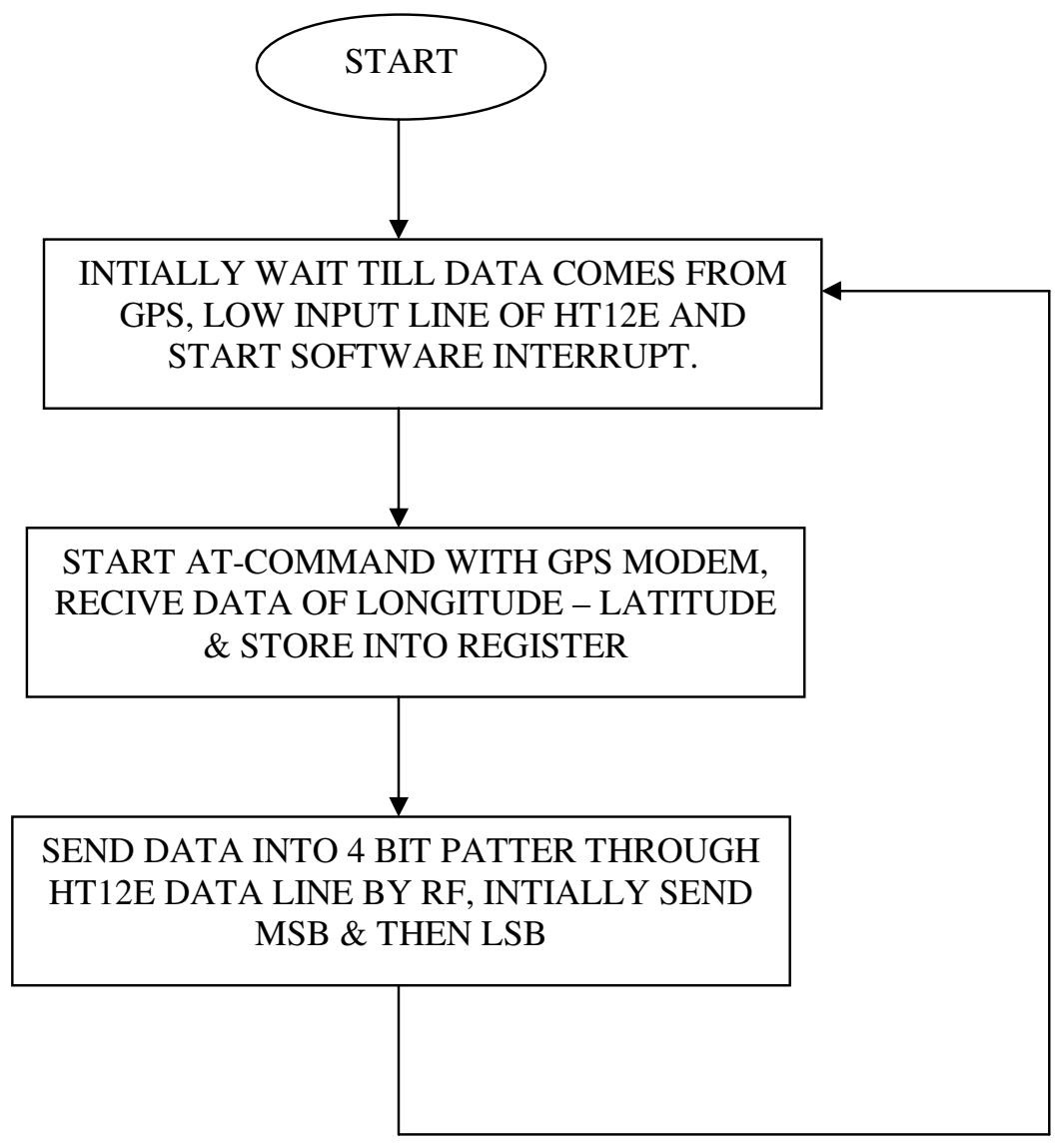

Figure. 1. Flowchart for Transmitter 


\subsection{FLOWCHART FOR RECEIVER:}

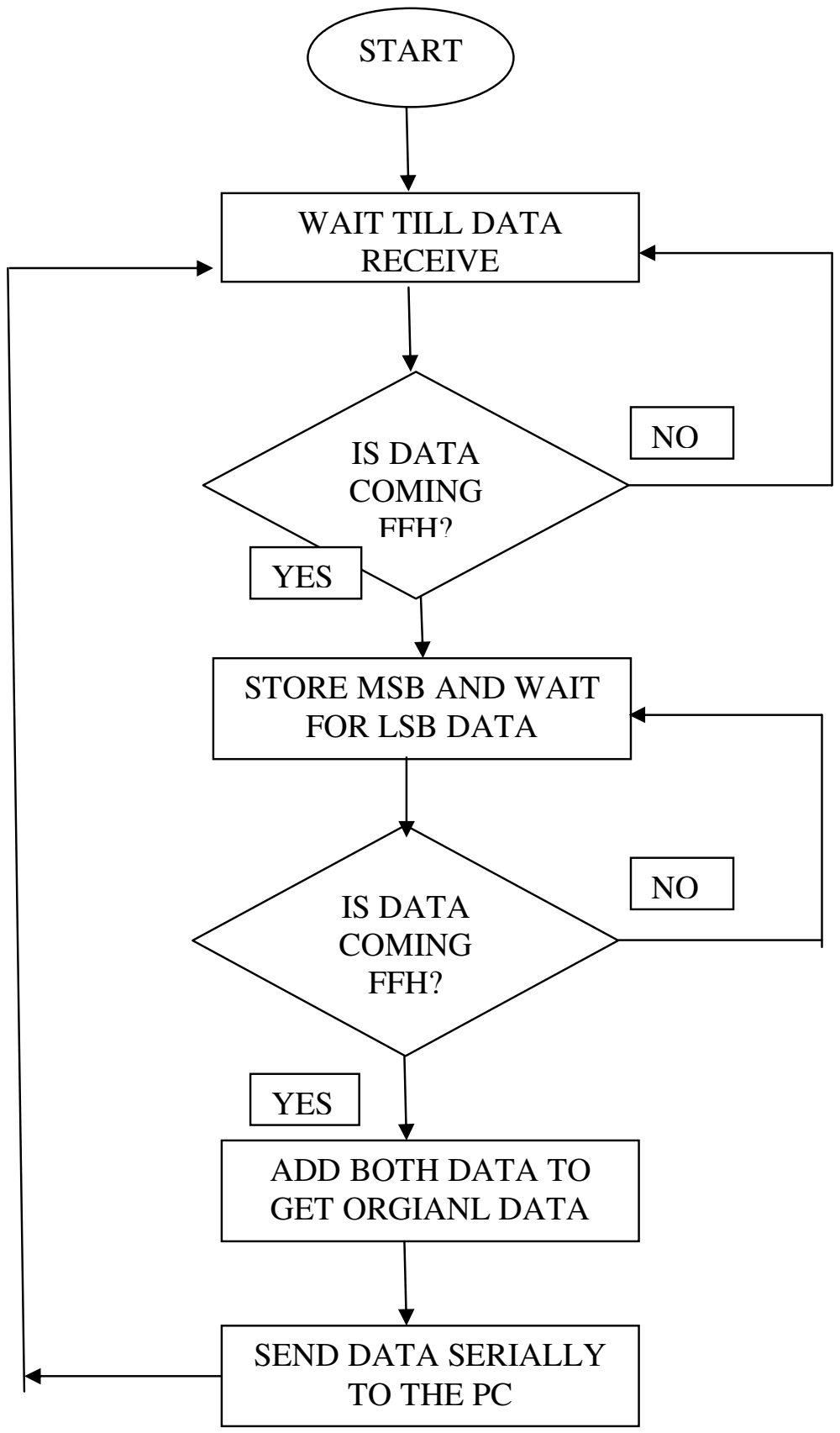

Figure. 2. Flowchart for Receiver 


\section{RESULT}

\subsection{HARDWARE OF TRANSMITTER}

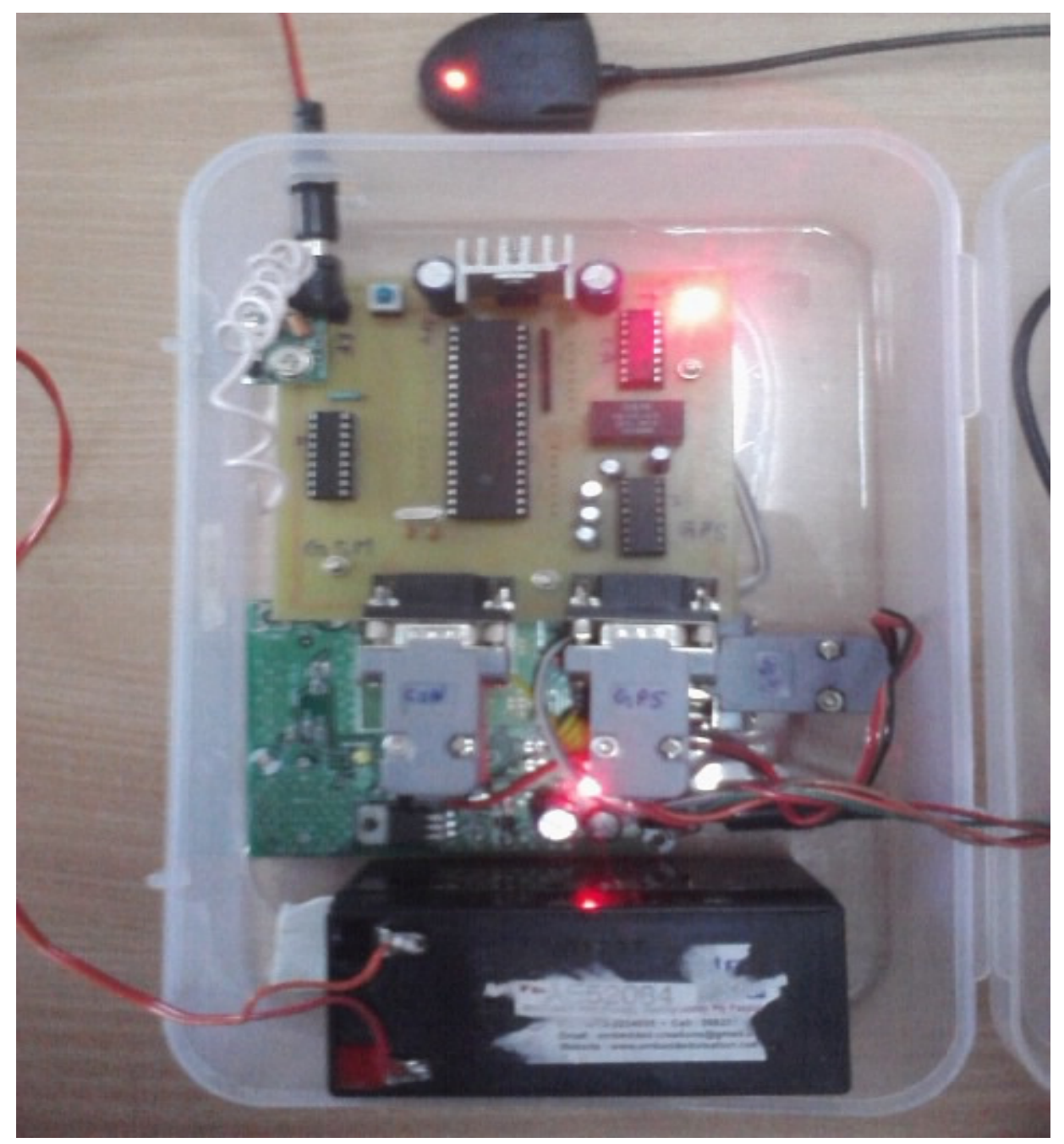

Figure. 3. Hardware of Transmitter 


\subsection{HARDWARE OF RECEIVER}

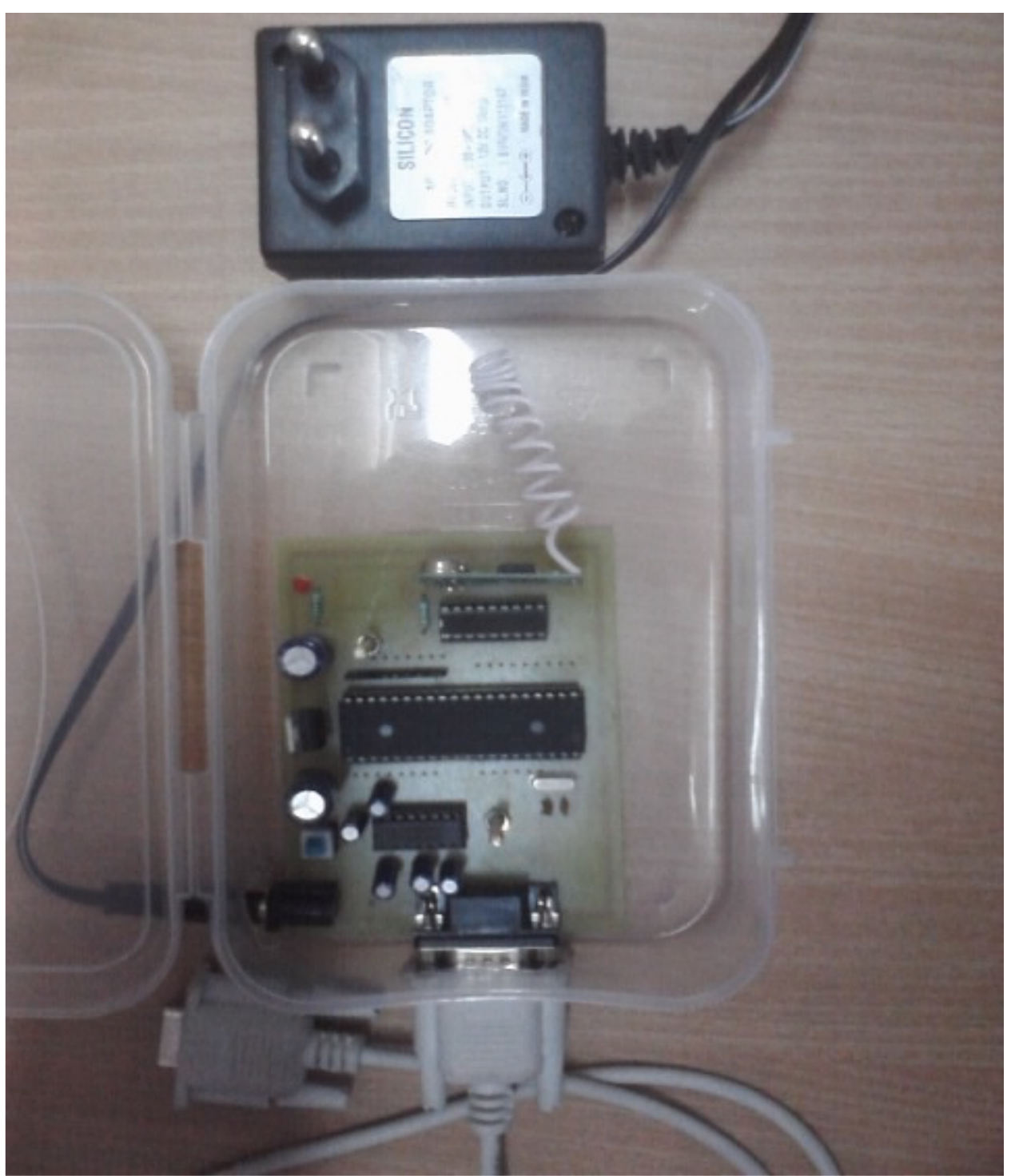

Figure. 4. Hardware of Transmitter

\section{Conclusions}

1) Vehicle tracking system is used generally for improving overall productivity which offers better return on your investments. For handling larger job loads within a time route planning is important. both for personal as well as for business purpose, Vehicle tracking improves safety and security, communication medium, performance 
International Journal of Distributed and Parallel Systems (IJDPS) Vol.3, No.4, July 2012

monitoring and it will increase productivity. So in future it will play a major role in our day-to-day living.

2) The Vehicle tracking system is a the tracking device which is generally operated by GPS is attached with the vehicle. satellite signals is first received by it and then it determines its position co-ordinates with latitude and longitude. These coordinates are generally observed on a computer screen and by using mapping software we can see the exact position of our vehicle. generally vehicle tracking technology user can access the information of a vehicle based on vehicle's position, speed and distance traveled and duration of each stoppage with a central operating center by entering the mobile number of user through mobile phones or websites using SMS or Internet. vehicletracking technology is advantageous for tracking and monitoring both commercial and passenger vehicle. as concerned with personal vehicle tracking, it allows recovering our stolen vehicle by pin pointing that gives the exact location.

\section{ACKNOWLEDGEMENTS} project.

I thankful to all my friends who directly or indirectly help me for completing this

The motivating factor for this project was the inspiration given to me by my husband Mr.P.B.Kamble he has given many valuable suggestions and encouraging generously throughout.

I wish to convey our gratitude to my family member. With their inspiration and encouragement, it is possible me to complete this project within time.

\section{REFERENCES}

[1] Theodore, S. Rappaport. Wireless Communications: Principles \& Practice, Prentice Hall, New Jersey, 1996

[2] C.A. Balanis, Antenna Theory: Analysis and Design, John Wiley and Sons, New York, 1997.

[3] Www.trackersystems.net/ - United States

[4] Lal, C. Godara. Applications of Antenna Arrays to mobile Communications, Part I Performance Improvement, feasibility, and System Considerations. Proceedings of the IEEE, Vol. 85, No. 7, July 1997.

[5] Elliott D. Kaplan, Christopher J. Hegarty - 2006, Understanding GPS: principles and applications

[6] http://www.tarzan.co.in/

[7] Introduction to Gps: The Global Positioning System ,Ahmed El-Rabbany

[8] www.trackingtheworld.com/ 
International Journal of Distributed and Parallel Systems (IJDPS) Vol.3, No.4, July 2012

\section{Author}

Mrs. K. P. Kamble

Short Biography

Mrs. K. P. Kamble holds a B.E. degree in 2002 from Nagpur University and M.E. degree in 2004 from S.R.T.M.U. Nanded in Electronics Engineering. She has presented papers in international conference snd national conference. Her research focuses on Digital Image Processing,Digital Signal Processing and Fuzzy Logic and Neural Network.

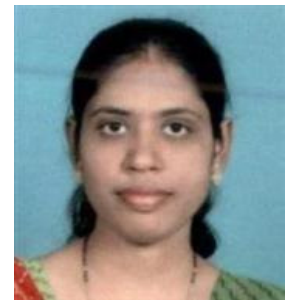

